\title{
Microsatellite Instability and $K R A S$ Mutation in Stage IV Colorectal Cancer: Prevalence, Geographic Discrepancies, and Outcomes From the National Cancer Database
}

\author{
Johannes Uhlig, MD, MPH ${ }^{1,2}$; Michael Cecchini, MD, ; Amar Sheth, BS'; Stacey Stein, MD ${ }^{3,4}$; \\ Jill Lacy, MD ${ }^{3,4}$; and Hyun S. Kim, MD, MHS ${ }^{1,3,4}$
}

\section{ABSTRACT}

Background: This study sought to assess microsatellite and KRAS status, prevalence, and impact on outcome in stage IV colorectal cancer (CRC). Materials and Methods: The 2010 to 2016 US National Cancer Database was queried for adult patients with stage IV CRC. Prevalence of microsatellite status (microsatellite instabilityhigh [MSI-H] or microsatellite stable [MSS]) and KRAS status (KRAS mutation or wild-type) of the primary CRC was assessed. Overall survival (OS) was evaluated using multivariable Cox proportional hazards models in patients with complete data on both microsatellite and KRAS status and information on follow-up. Results: Information on microsatellite and KRAS status was available for 10,844 and 25,712 patients, respectively, and OS data were available for 5,904 patients. The overall prevalence of MSI-H status and KRAS mutation was $3.1 \%$ and $42.4 \%$, respectively. Prevalence of MSI-H ranged between $1.6 \%$ (rectosigmoid junction) and 5.2\% (transverse colon), and between $34.7 \%$ (sigmoid colon) and $58.2 \%$ (cecum) for KRAS mutation. MSI-H rates were highest in East North Central US states (4.1\%), and KRAS mutation rates were highest in West South Central US states (44.1\%). Multivariable analyses revealed longer OS for patients with KRAS wild-type versus mutation status (hazard ratio [HR], $0.91 ; 95 \% \mathrm{Cl}, 0.85-0.97 ; P=.004$ ), those with MSS versus $\mathrm{MSI}-\mathrm{H}$ status ( $\mathrm{HR}, 0.75 ; 95 \% \mathrm{Cl}, 0.62-0.9 ; P=.003)$, and those with left-sided versus right-sided CRC (multivariable HR, 0.65; $95 \% \mathrm{Cl}, 0.6-0.7 ; P<.001)$. The effect of KRAS mutation further varied with CRC site and microsatellite status ( $P=.002$ for interaction). Conclusions: Depending on the primary site and US geography, stage IV CRC shows distinct mutational behavior. KRAS mutation, MSI-H, and primary CRC sidedness independently affect OS and interact with distinct prognostic profiles. Generically classifying adenocarcinomas at different sites as CRC might deprecate this diversity.

J Natl Compr Canc Netw 2021;19(3):307-318 doi: 10.6004/jnccn.2020.7619

\footnotetext{
${ }^{1}$ Section of Interventional Radiology, Yale School of Medicine, New Haven, Connecticut; ${ }^{2}$ Department of Diagnostic and Interventional Radiology, University Medical Center Goettingen, Goettingen, Germany; and ${ }^{3}$ Section of Medical Oncology, Yale School of Medicine, and ${ }^{4}$ Yale Cancer Center, Yale School of Medicine, New Haven, Connecticut.
}

\section{Background}

Colorectal cancer (CRC) is the third most common malignancy worldwide, accounting for approximately 1.9 million new cases and 880,000 deaths in 2018. ${ }^{1}$ Especially in Western countries, CRC incidence has declined over the past decade, which might be attributable to implementation of colonoscopic screening, use of nonsteroidal anti-inflammatory drugs, and changes in lifestyle and diet. ${ }^{2,3}$ Concurrently, major advances have been made in CRC treatment, especially regarding the combination of cytotoxic agents and introduction of targeted therapy in metastatic settings. ${ }^{4,5}$

Genomic instability is of crucial importance for CRC development and progression and includes several mechanisms, one of which is the loss of DNA mismatch repair (MMR) proteins, which results in microsatellite instability-high (MSI-H) tumors. ${ }^{6}$ Mutation of the KRAS oncogene, which is downstream from the epidermal growth factor receptor (EGFR), is another genomic abnormality in CRC. ${ }^{7}$

Both MSI-H and KRAS mutation affect CRC treatment strategies: although immune checkpoint inhibitors have been shown to be effective in treatment of advanced solid tumors that are MSI- $\mathrm{H},{ }^{8,9}$ KRAS mutations have been reported to mediate resistance to antiEGFR treatment. ${ }^{10,11}$ MSI and KRAS status therefore impact individualized treatment strategies for patients with CRC, particularly those with advanced or metastatic CRC (mCRC). Although BRAF mutations have also been described in $\mathrm{mCRC}$, therapeutic targeting is challenging, which has been linked to tumoral resistance mechanisms. ${ }^{12}$

Furthermore, MSI-H and defects in DNA MMR genes are the mutational hallmarks in patients with Lynch

See JNCCN.org for supplemental online content. 
syndrome, who have a high propensity for CRC at an early age. ${ }^{13}$ Lynch syndrome is diagnosed in approximately $20 \%$ of patients with MSI-H CRC. ${ }^{14}$ Given the implications for treatment and familial CRC risk, NCCN recommends MSI and MMR testing in all newly diagnosed CRC cases. ${ }^{15}$

Besides hereditary factors, there is increasing evidence that MSI and KRAS status are affected by the primary CRC location. ${ }^{16,17}$ Still, to date, there are scarce US national data on the prevalence of MSI-H and KRAS mutation that account for the primary cancer sidedness. In this study, we evaluated the prevalence of microsatellite and KRAS status in stage IV CRC using a largescale US national database and assessed their effect on outcomes of patients with CRC.

\section{Materials and Methods}

This study received approval from the Yale School of Medicine Institutional Review Board and was HIPAA compliant.

\section{Study Collective}

The National Cancer Database (NCDB), jointly sponsored by the American College of Surgeons and the American Cancer Society, contains approximately 34 million records from hospital cancer registries in the United States. It captures approximately $70 \%$ of newly diagnosed cancer cases annually in the United States. The NCDB was queried from 2010 to 2016 for patients who had the following diagnoses: pathologically confirmed AJCC stage IV colorectal adenocarcinoma of the cecum (C18.0), ascending colon (C18.2), hepatic flexure of the colon (C18.3), transverse colon (C18.4), splenic flexure of the colon (C18.5), descending colon (C18.6), sigmoid colon (C18.7), rectosigmoid junction (C19.9), and rectum (C20.9). Analyses were limited to cases with information on microsatellite status, KRAS status, and known stage IV disease. We excluded patients aged $<18$ years and those with overlapping lesions of the colon (C18.8); colon, not specified (C18.9); and gastrointestinal, not specified (C26.0). Patients were also excluded if their microsatellite status was obtained via immunologic testing and reported as "instability, not otherwise specified." Survival analyses were limited to patients with complete information on microsatellite and KRAS status, follow-up time, and survival status.

\section{Variables}

Patient comorbidities were reported using the CharlsonDeyo comorbidity index (CCI) score, stratifying patients into CCI scores of $0,1,2$, and $\geq 3$. Microsatellite status was assessed via PCR in tumor samples and stratified as MSI-H, MSI-low (MSI-L), and microsatellite stable (MSS). MSI-L and MSS were grouped for all analyses in this study. Patients evaluated for microsatellite status via immunohistochemistry were not considered for our analyses. KRAS status was stratified as $K R A S$ mutation and wild-type. Radiotherapy was classified as local CRC radiotherapy, radiotherapy for CRC metastases, yttrium-90 radioembolization, and no radiotherapy.

Geographic information was provided as broader US state regions to facilitate anonymization, including the following regions: New England (Connecticut, Maine, Massachusetts, New Hampshire, Rhode Island, and Vermont), Middle Atlantic (New Jersey, New York, and Pennsylvania), East North Central (Illinois, Indiana, Michigan, Ohio, and Wisconsin), West North Central (Iowa, Kansas, Minnesota, Missouri, Nebraska, North Dakota, and South Dakota), South Atlantic (Delaware, Florida, Georgia, Maryland, North Carolina, South Carolina, Virginia, District of Columbia, and West Virginia), East South Central (Alabama, Kentucky, Mississippi, and Tennessee), West South Central (Arkansas, Louisiana, Oklahoma, and Texas), Mountain (Arizona, Colorado, Idaho, Montana, Nevada, New Mexico, Utah, and Wyoming), and Pacific (Alaska, California, Hawaii, Oregon, and Washington).

\section{Outcomes}

Two primary outcomes of interest were defined a priori: (1) correlation of microsatellite and KRAS status with other CRC factors (cancer site, grade, stage, and metastatic status) and (2) impact of microsatellite and KRAS status on CRC overall survival (OS) and interaction with primary CRC sidedness.

\section{Statistical Analyses}

Continuous variables are provided as median with interquartile range and categorical variables as absolute number with percent. Continuous variables were compared using the Wilcoxon rank-sum test and categorical variables using the chi-square test. Logistic regression models were used to assess the likelihood of MSI-H and KRAS mutation in separate analyses. Due to concerns for reverse causation, metastatic status and cancer treatment were not considered.

OS was evaluated using univariate and multivariable Cox proportional hazards models. Variables were considered for inclusion in multivariable models based on univariate significance and were retained in the final multivariable model if $P<.05$. For multivariable modeling, tumor location was combined into right-sided CRC (CRC of the cecum and ascending and transverse colon) and left-sided CRC (CRC of the descending and sigmoid colon and the rectum). Year of CRC diagnosis was included in the final multivariable model to account for changes in therapy over time. Statistical 

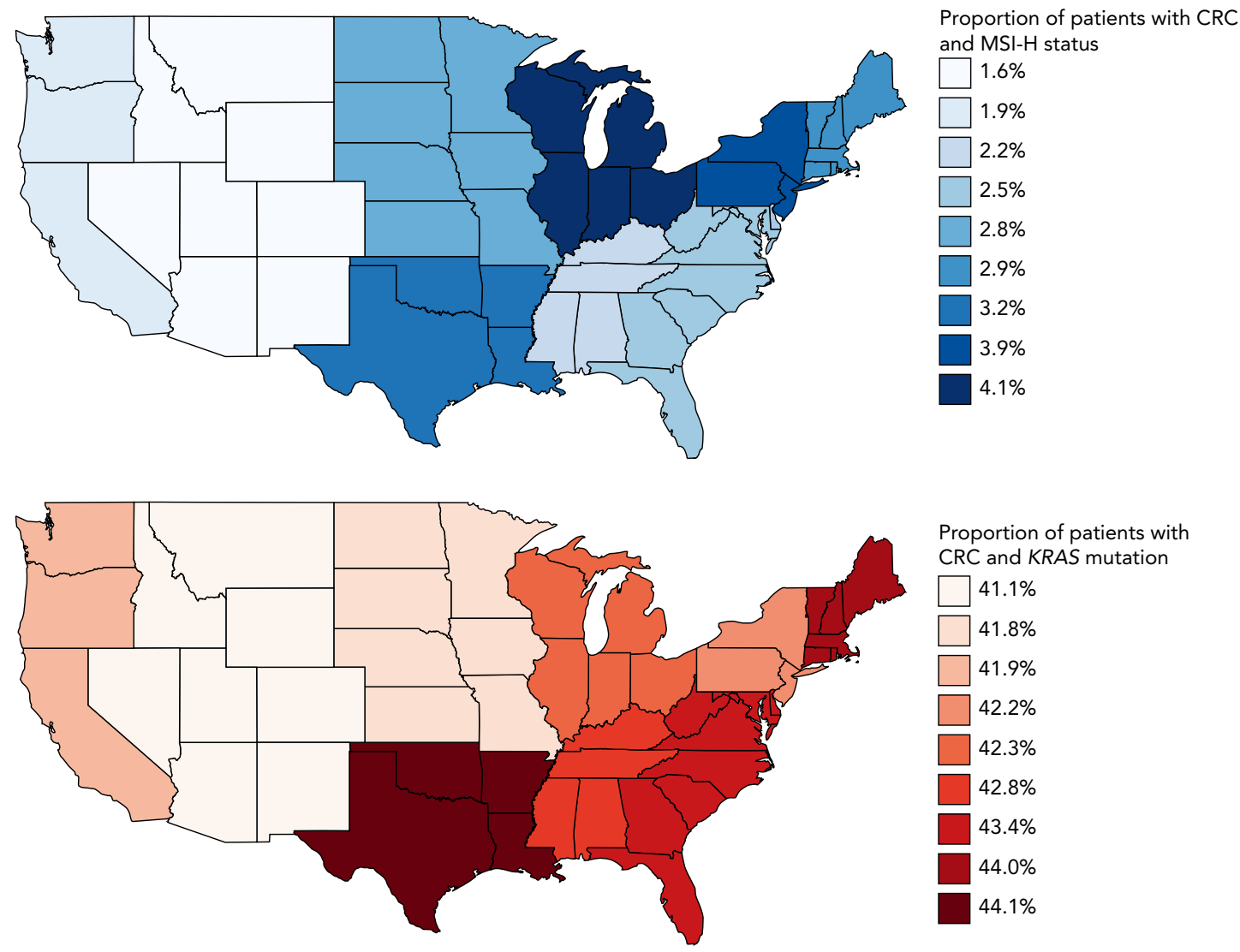

Figure 1. US geographic variation in MSI-H and KRAS status among patients with stage IV CRC adenocarcinoma. Abbreviations: CRC, colorectal cancer; MSI-H, microsatellite instability-high.

interaction analyses were planned a priori between microsatellite status, KRAS status, and primary tumor sidedness.

All statistical analyses were performed using $\mathrm{R}$ version 3.4.3 (R Foundation for Statistical Computing) and RStudio version 1.1.414 (RStudio, Inc.). An $\alpha$-level of .05 was chosen for statistical significance. All $P$ values are 2-sided.

\section{Results}

Among 73,603 patients with mCRC and data on metastatic status, information on microsatellite status was available for $10,844(14.7 \%)$ and on KRAS status for 25,712 (34.9\%); these datasets were used for epidemiologic modeling. For 5,904 patients, information on both microsatellite and KRAS status was available (supplemental eFigure 1 and eTable 1, available with this article at JNCCN.org), which was used to assess OS and interactions between variables. The overall prevalence of MSI-H status and KRAS mutation was $3.1 \%$ and $42.4 \%$, respectively. The prevalence of KRAS mutation was $28.9 \%$ among patients with MSI-H CRC.
Association of CRC Genomic Abnormalities With Geographic, Sociodemographic, and Cancer Factors Multivariable logistic regression analyses (supplemental eTables 1 and 2) revealed that the likelihood of KRAS mutation was associated with female sex (odds ratio, 1.10; 95\% CI, 1.04-1.15; $P<.001$ ) and African American race (odds ratio, 1.58; 95\% CI, $1.40-1.72 ; P<.001)$. Furthermore, microsatellite and KRAS status independently varied according to US region (Figure 1): MSI-H prevalence was highest in East North Central states $(4.1 \%)$ and prevalence of KRAS mutation was highest in West South Central states $(44.1 \%)$. Primary CRC sidedness was another independent predictor of microsatellite and KRAS status (Figure 2, supplemental eTables 3 and 4): the prevalence of MSI-H ranged between $1.6 \%$ (rectosigmoid junction) and $5.2 \%$ (transverse colon), and between $58.2 \%$ (cecum) and $34.7 \%$ (sigmoid colon) for KRAS mutation.

Exploratory univariate analyses revealed that MSI-H was associated with fewer distant metastases than MSS (ie, $64.4 \%$ hepatic metastases in MSI-H vs $75.4 \%$ in MSS) (Tables 1 and 2). In contrast, KRAS mutation was associated 


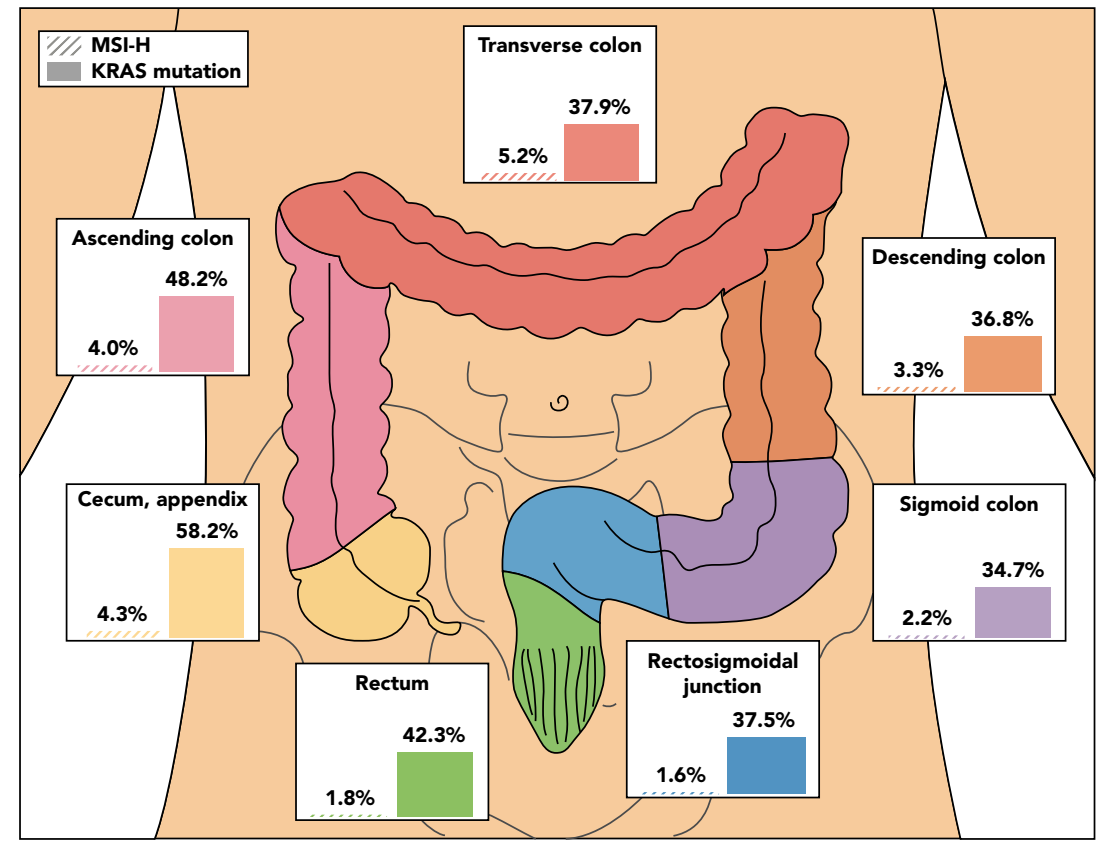

Figure 2. MSI-H and KRAS mutation prevalence according to primary CRC site.

Abbreviations: CRC, colorectal cancer; MSI-H, microsatellite instability-high.

with higher metastatic probability (ie, $29.8 \%$ lung metastases with KRAS mutation vs $20.7 \%$ with KRAS wildtype).

\section{CRC Mutation Status: Impact on OS and Interaction \\ With Tumor Location}

For survival analyses, we evaluated a total of 5,904 patients with data on KRAS mutation and microsatellite status and complete information on follow-up. Median follow-up time in this cohort was 44.5 months (interquartile range, 27.1-61.8 months). Univariate analyses revealed that patients with KRAS wild-type had longer OS than those with KRAS mutation (hazard ratio [HR], 0.71; 95\% CI, 0.59-0.85; $P<.001$ ), and those with MSS had longer OS than those with MSI-H (HR, 0.82; 95\% CI, $0.77-0.88 ; P<.001)$. Furthermore, CRC sidedness affected patient outcomes, with longer OS for left-sided versus righted-sided CRC (HR, 0.64; 95\% CI, 0.60-0.68; $P<.001$ ). OS differences are summarized in Figure 3, and corresponding OS rates are summarized in supplemental eTable 4.

After adjustment for patient-, tumor-, and treatmentlevel variables, microsatellite status, KRAS status, and primary CRC site emerged as independent predictors of OS (Table 3). Longer OS was confirmed for patients with KRAS wild-type versus mutation (multivariable HR, $0.91 ; 95 \%$ CI, $0.85-0.97 ; P=.004$ ), those with MSS versus MSI-H (multivariable HR, 0.75; 95\% CI, $0.62-0.90 ; P=.003$ ), and those with left-sided versus right-sided CRC (multivariable HR, 0.65; 95\% CI, 0.60-0.70; $P<.001$ ).

Furthermore, a statistical interaction between microsatellite status, KRAS status, and primary CRC site was evident (4- $d f$ multivariable interaction test, $P=.002$ ). For example, the effect of KRAS wild-type on OS was stronger in left-sided CRC (KRAS wild-type vs mutation: HR, 0.77; 95\% CI, 0.71-0.85; $P<.001$ ) than in right-sided CRC (KRAS wild-type vs mutation: HR, 1.03; 95\% CI, 0.93-1.13; $P=.595$ ) (Figure 4).

\section{Discussion}

In the large-scale NCDB, the overall rate of MSI-H was $3.1 \%$ and that of KRAS mutation was $42.4 \%$ in patients with stage IV CRC. MSI rates in our study are comparable to those published for advanced CRC. For example, Fujiyoshi et $\mathrm{al}^{18}$ reported an MSI-H prevalence of $4.1 \%$ in 401 patients with stage IV CRC. Furthermore, the KRAS mutation prevalence of $42.4 \%$ in our cohort is also similar to that reported elsewhere. For instance, Lowe et $\mathrm{al}^{19}$ reported $35.9 \%$ KRAS mutation prevalence in a meta-analysis of patients with metastatic CRC, whereas Kafatos et $\mathrm{al}^{20}$ showed RAS mutations (combined KRAS and NRAS) in $43.6 \%$ of patients with metastatic CRC pooled from 12 primary data sources.

In our study, KRAS mutation rates varied with patient demographics, with a higher rate of KRAS mutation seen in female African American individuals, which might contribute to poorer CRC outcomes observed in 


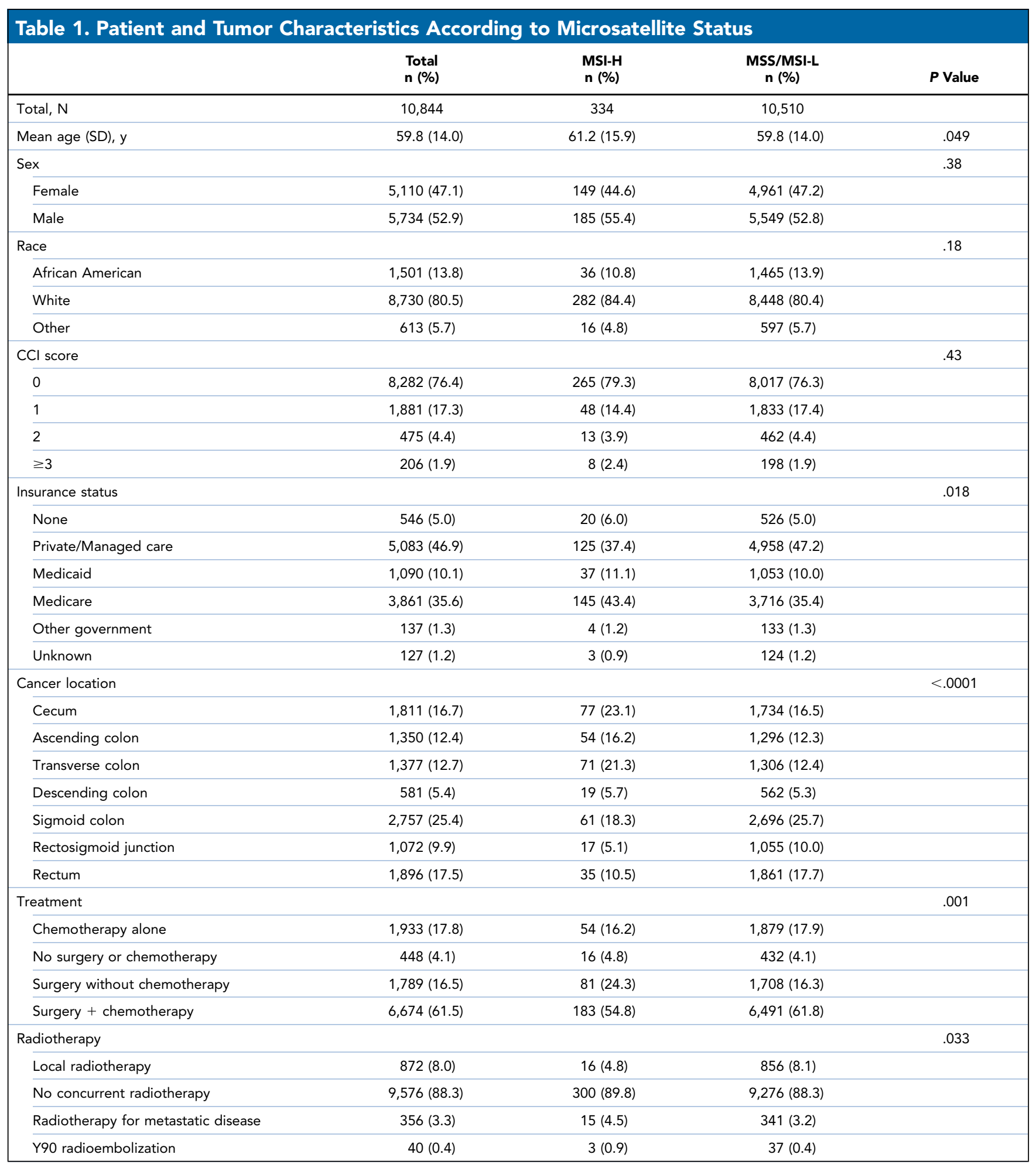

this population. ${ }^{21}$ Race- and sex-specific differences in KRAS status differences are supported by earlier literature on stage III CRC and might be attributable to varying neoplasia pathways and enzyme activity. ${ }^{22}$
Patient age was not associated with MSI-H status in our multivariable analyses, which is counterintuitive, given that $20 \%$ of patients with MSI-H CRC are reported to have Lynch syndrome, with disease typically 
Table 1. Patient and Tumor Characteristics According to Microsatellite Status (cont.)

\begin{tabular}{|c|c|c|c|c|}
\hline & $\begin{array}{l}\text { Total } \\
\text { n (\%) }\end{array}$ & $\begin{array}{c}\text { MSI-H } \\
\text { n (\%) }\end{array}$ & $\begin{array}{c}\text { MSS/MSI-L } \\
\text { n (\%) }\end{array}$ & $P$ Value \\
\hline Metastases & & & & $<.0001$ \\
\hline To 1 distant organ & $7,224(66.6)$ & $192(57.5)$ & $7,032(66.9)$ & \\
\hline To $\geq 2$ distant organs & $1,646(15.2)$ & $38(11.4)$ & $1,608(15.3)$ & \\
\hline Liver metastases & & & & $<.0001$ \\
\hline Yes & $8,138(75.0)$ & $215(64.4)$ & $7,923(75.4)$ & \\
\hline No & $2,706(25.0)$ & $119(35.6)$ & $2,587(24.6)$ & \\
\hline Lung metastases & & & & .0004 \\
\hline Yes & $374(3.4)$ & $19(5.7)$ & $355(3.4)$ & \\
\hline No & $10,470(96.6)$ & $315(94.3)$ & $10,155(96.6)$ & \\
\hline Brain metastases & & & & .37 \\
\hline Yes & $98(0.9)$ & $1(0.3)$ & $97(0.9)$ & \\
\hline No & $10,746(99.1)$ & $333(99.7)$ & $10,413(99.1)$ & \\
\hline Treatment facility type & & & & .80 \\
\hline Academic center & $3,688(34.0)$ & $107(32.0)$ & $3,581(34.1)$ & \\
\hline Nonacademic center & $6,376(58.8)$ & $192(57.5)$ & 6,184 (58.8) & \\
\hline Suppressed for age $<39$ y & $780(7.2)$ & $35(10.5)$ & $745(7.1)$ & \\
\hline New England & $654(6.0)$ & $19(5.7)$ & $635(6.0)$ & \\
\hline Pacific & $1,343(12.4)$ & $25(7.5)$ & $1,318(12.5)$ & \\
\hline South Atlantic & $2,059(19.0)$ & $52(15.6)$ & $2,007(19.1)$ & \\
\hline West North Central & $709(6.5)$ & $20(6.0)$ & $689(6.6)$ & \\
\hline West South Central & $696(6.4)$ & $22(6.6)$ & $674(6.4)$ & \\
\hline
\end{tabular}

Continuous variables were compared between subgroups using the Wilcoxon rank-sum test, and categorical variables were compared using the chi-square test. Abbreviations: CCI, Charlson-Deyo comorbidity index; MSI-H, microsatellite instability-high; MSI-L microsatellite instability-low, MSS, microsatellite status-stable; Y90, yttrium-90.

manifesting at a younger age than CRC in other patients. ${ }^{13,14}$ This discrepancy might be attributable to a low proportion of patients with Lynch syndrome in our cohort and to the anonymization process of the NCDB with suppressed facility location for patients aged $<39$ years.

Our findings further reveal that CRC genomic abnormalities independently vary with US geography in the NCDB population, with the highest MSI-H prevalence in East North Central states (Illinois, Indiana, Michigan, Ohio, and Wisconsin) and the highest KRAS mutation prevalence in West South Central states (Arkansas, Louisiana, Oklahoma, and Texas). Although this variability could be attributable to the patients' mutational susceptibility, differences in environmental and socioeconomic factors, dietary behavior, and CRC screening compliance might also contribute. CRC has been described as an environmentally 


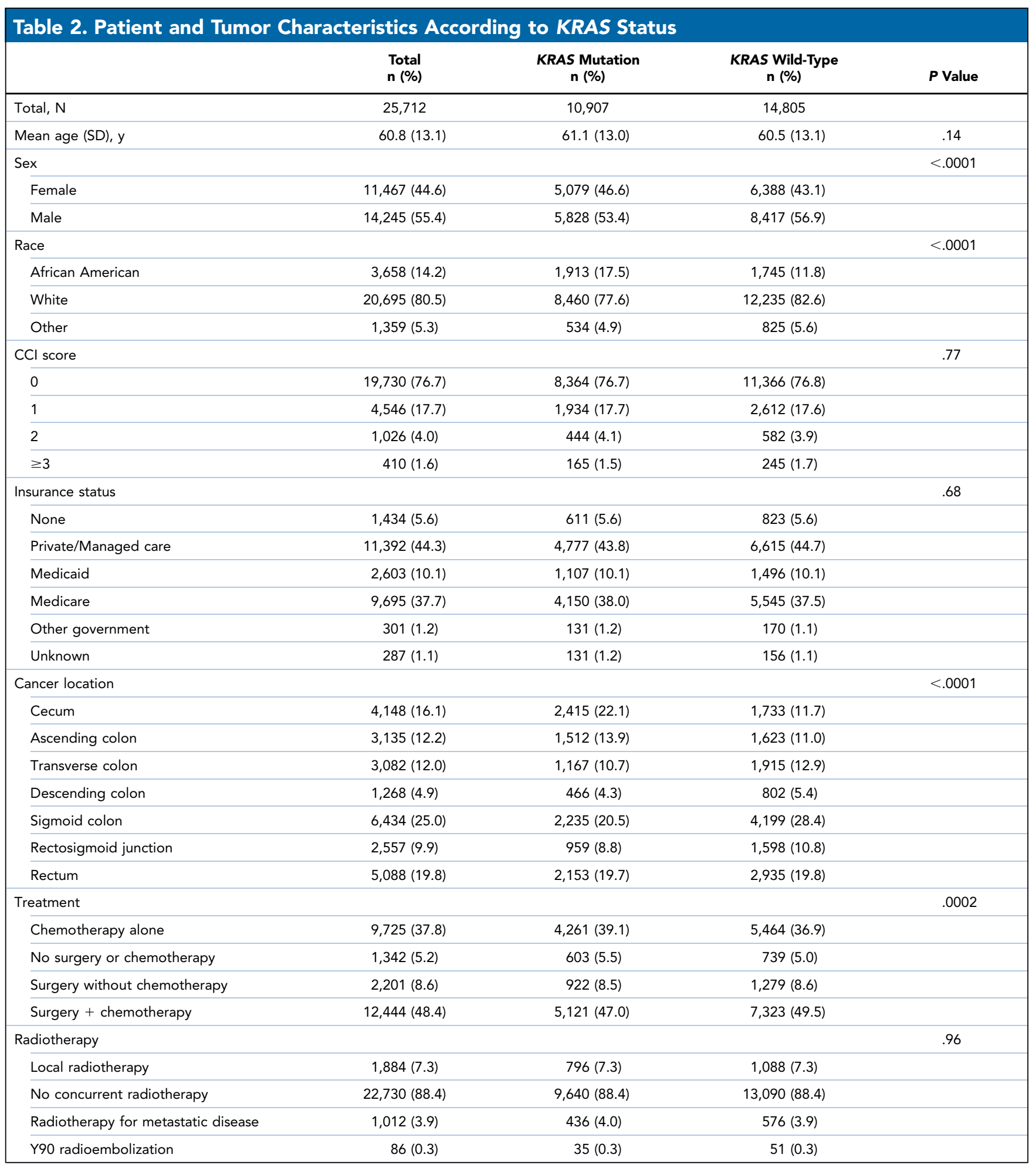

mediated entity. For example, it has been shown that immigrants assume the CRC risk of their new environment within one generation. ${ }^{23}$ Diets rich in processed and red meat have been linked to a higher CRC risk, ${ }^{24}$ as have smoking and excessive alcohol consumption. ${ }^{25,26}$ Still, to date, there are only sparse data on geographic variability of CRC mutations. Turpin et $\mathrm{al}^{27}$ evaluated patients with CRC from northern France and showed spatial heterogeneity that might 
Table 2. Patient and Tumor Characteristics According to KRAS Status (cont.)

\begin{tabular}{|c|c|c|c|c|}
\hline & $\begin{array}{l}\text { Total } \\
\text { n (\%) }\end{array}$ & $\begin{array}{l}\text { KRAS Mutation } \\
\mathrm{n}(\%)\end{array}$ & $\begin{array}{c}\text { KRAS Wild-Type } \\
\text { n (\%) }\end{array}$ & $P$ Value \\
\hline Metastases & & & & $<.0001$ \\
\hline Distant, not specified & $1,260(4.9)$ & $467(4.3)$ & $793(5.4)$ & \\
\hline To 1 distant organ & $16,633(64.7)$ & $6,805(62.4)$ & $9,828(66.4)$ & \\
\hline To $\geq 2$ distant organs & $5,497(21.4)$ & $2,779(25.5)$ & $2,718(18.4)$ & \\
\hline No distant organ metastases & $798(3.1)$ & $283(2.6)$ & $515(3.5)$ & \\
\hline Peritoneal metastases & $1,524(5.9)$ & $573(5.3)$ & $951(6.4)$ & \\
\hline Liver metastases & & & & .039 \\
\hline Yes & $20,423(79.4)$ & $8,730(80.0)$ & $11,693(79.0)$ & \\
\hline No & $5,289(20.6)$ & $2,177(20.0)$ & $3,112(21.0)$ & \\
\hline Lung metastases & & & & $<.0001$ \\
\hline Yes & $6,314(24.6)$ & $3,252(29.8)$ & $3,062(20.7)$ & \\
\hline No & $19,398(75.4)$ & $7,655(70.2)$ & $11,743(79.3)$ & \\
\hline Bone metastases & & & & .01 \\
\hline Yes & $1,194(4.6)$ & $550(5.0)$ & $644(4.3)$ & \\
\hline No & $24,518(95.4)$ & $10,357(95.0)$ & $14,161(95.7)$ & \\
\hline Brain metastases & & & & $<.0001$ \\
\hline Yes & $322(1.3)$ & $182(1.7)$ & $140(0.9)$ & \\
\hline No & $25,390(98.7)$ & $10,725(98.3)$ & $14,665(99.1)$ & \\
\hline Treatment facility type & & & & .22 \\
\hline Academic center & $8,526(33.2)$ & $3,682(33.8)$ & $4,844(32.7)$ & \\
\hline Nonacademic center & $15,780(61.4)$ & $6,685(61.3)$ & $9,095(61.4)$ & \\
\hline Suppressed for age $<39$ y & $1,406(5.5)$ & $540(5.0)$ & $866(5.8)$ & \\
\hline Treatment facility location & & & & .050 \\
\hline East North Central & $4,316(16.8)$ & $1,825(16.7)$ & $2,491(16.8)$ & \\
\hline East South Central & $1,435(5.6)$ & $614(5.6)$ & $821(5.5)$ & \\
\hline Suppressed for age $<39$ y & $1,406(5.5)$ & $540(5.0)$ & $866(5.8)$ & \\
\hline Middle Atlantic & 4,019 (15.6) & $1,698(15.6)$ & $2,321(15.7)$ & \\
\hline Mountain & $1,179(4.6)$ & $484(4.4)$ & $695(4.7)$ & \\
\hline New England & $1,360(5.3)$ & $599(5.5)$ & $761(5.1)$ & \\
\hline Pacific & $2,827(11.0)$ & $1,184(10.9)$ & $1,643(11.1)$ & \\
\hline South Atlantic & $5,129(19.9)$ & $2,228(20.4)$ & $2,901(19.6)$ & \\
\hline West North Central & $2,078(8.1)$ & $869(8.0)$ & $1,209(8.2)$ & \\
\hline West South Central & $1,963(7.6)$ & $866(7.9)$ & $1,097(7.4)$ & \\
\hline
\end{tabular}

Continuous variables were compared between subgroups using the Wilcoxon rank-sum test, and categorical variables were compared using the chi-square test. Abbreviations: $\mathrm{CCl}$, Charlson-Deyo comorbidity index; Y90, yttrium-90.

correlate with environmental factors, such as proximity to major highways and large cities. The association of KRAS mutation with African American race, female sex, and West South Central US state residence further raises the question of whether the geographic differences of KRAS status are affected by racial distribution differences.

Our data further showed that microsatellite and KRAS status varied with the primary tumor side. In tendency, both MSI-H and KRAS mutation were more common in right-sided versus left-sided CRC, whereas specific primary CRC locations showed distinct mutational profiles. These results are supported by Sinicrope et $\mathrm{al}^{16}$ who described site-specific KRAS mutation and DNA MMR defects in 3,018 patients with stage III disease undergoing adjuvant chemotherapy, reporting higher KRAS mutation and MSI-H rates in right-sided CRC. Yamauchi et $\mathrm{al}^{17}$ described higher MSI-H incidence for CRC of stage I-IV in the proximal colon. Higher rates of KRAS mutation for right-sided stage II and III CRC are 
A
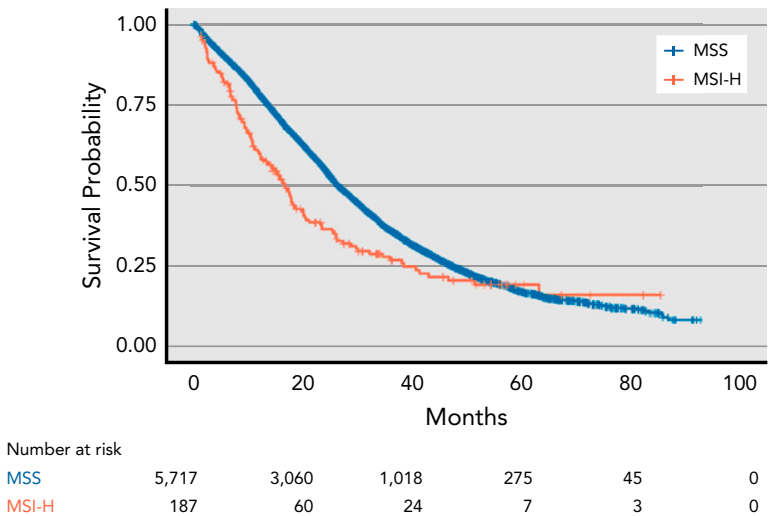

B

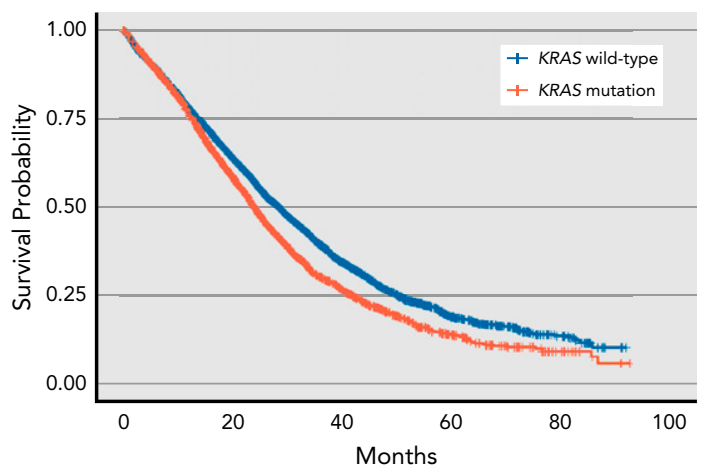

Number at risk

$\begin{array}{lllllll}\text { KRAS wild-type } & 3,538 & 1,927 & 675 & 198 & 33 & 0\end{array}$

$\begin{array}{llllll}\text { KRAS mutation } & 2,366 & 1,193 & 367 & 84 & 15\end{array}$

\section{C}

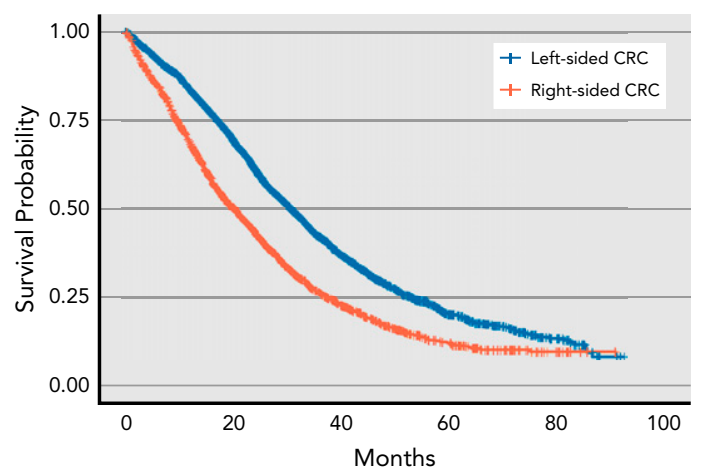

Number at risk

$\begin{array}{llllll}\text { Left-sided CRC } & 3,551 & 2,092 & 727 & 194 & 34\end{array}$

$\begin{array}{lllrll}\text { Right-sided CRC } & 2,353 & 1,028 & 315 & 88 & 14\end{array}$

Figure 3. Kaplan-Meier plots showing impact on OS of (A) microsatellite status, (B) KRAS status, and (C) primary CRC site.

Abbreviations: CRC, colorectal cancer; MSI, microsatellite instability-high; MSS, microsatellite status-stable; OS, overall survival.

also noted in analyses derived from The Cancer Genome Atlas (TCGA). ${ }^{28}$

The underlying mechanisms of these site-specific mutation rates are not fully understood. Differences in the embryologic origin might contribute, given that the
Table 3. Multivariable Cox Proportional Hazards Model Evaluating Overall Survival Based on CRC Mutation Status

\section{Variable}

HR $(95 \% \mathrm{Cl}) \quad P$ Value

CRC location

Right-sided

Left-sided

Ref

Left-sided

KRAS status

KRAS mutation

KRAS wild-type

$0.65(0.60-0.70)<.001$

Microsatellite status

MSI-H Ref

MSS

$0.75(0.62-0.90) \quad .003$

Age (per 1-y increment)

$1.01(1.01-1.02)<.001$

Sex

Female

Ref

Male

$1.04(0.97-1.11)$

.264

$\mathrm{CCl}$ score

0

Ref

$\geq 1$

$1.1(1.01-1.18) \quad .022$

Race

African American

Ref

Other

$0.97(0.88-1.07)$

.537

Metastases

To 1 distant organ

Ref

To $\geq 2$ distant organs

$1.45(1.33-1.59)<.001$

Other or unspecified metastatic status

$0.91(0.83-1.00)$

.063

Treatment facility type

Academic center

Ref

Nonacademic center

$1.25(1.16-1.34) \quad<.001$

Treatment

Chemotherapy alone

No surgery or chemotherapy

Ref

$3.5(2.89-4.23)<.001$

Surgery without chemotherapy

$1.05(0.93-1.19) \quad .426$

Surgery + chemotherapy

$0.51(0.47-0.55)<.001$

Radiotherapy

No concurrent radiotherapy

Ref

Local radiotherapy

$0.82(0.71-0.95) \quad .009$

Radiotherapy for metastatic disease

$1.1(0.93-1.31) \quad .272$

Y90 radioembolization

$1.16(0.70-1.94) \quad .56$

Year of CRC diagnosis

\begin{tabular}{lll}
\hline 2010 & Ref & \\
\hline 2011 & $0.83(0.72-0.95)$ & .009 \\
\hline 2012 & $0.97(0.85-1.10)$ & .632 \\
\hline 2013 & $0.99(0.87-1.13)$ & .88 \\
\hline 2014 & $1.02(0.90-1.17)$ & .722 \\
\hline 2015 & $1.14(0.99-1.31)$ & .063 \\
\hline
\end{tabular}

Abbreviations: $\mathrm{CCl}$, Charlson-Deyo comorbidity index; CRC, colorectal cancer $\mathrm{HR}$, hazard ratio; MSI-H, microsatellite instability-high; MSS, microsatellite status-stable; Y90, yttrium-90. 
A
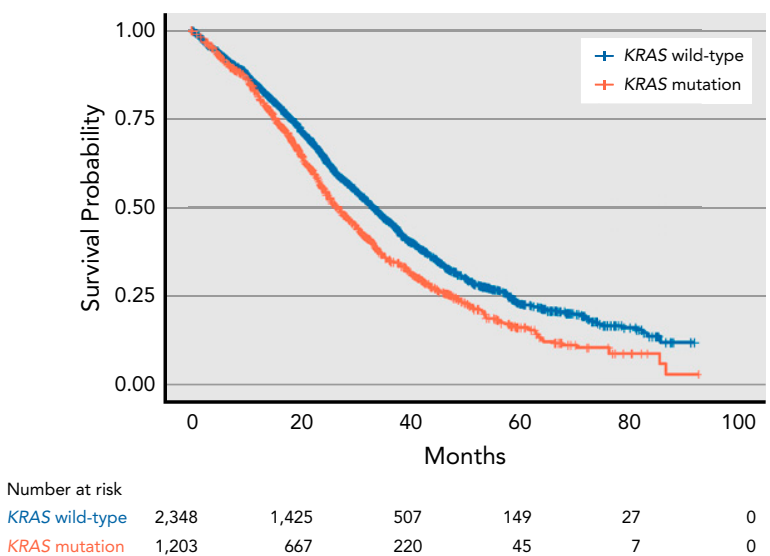

B

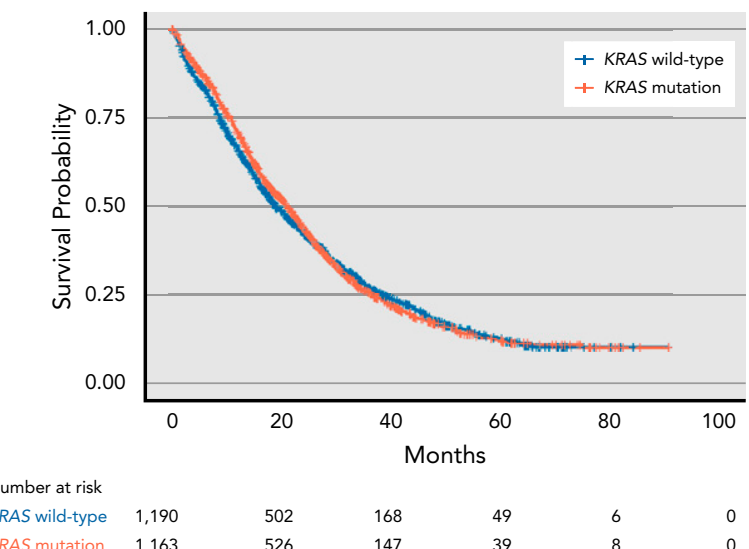

Figure 4. Kaplan-Meier plots showing differing effects of KRAS status according to microsatellite status and primary (A) left-sided versus $(B)$ right-sided colorectal cancer.

right-sided colon is derived from the midgut and the leftsided colon and rectum are derived from the hindgut. ${ }^{29}$ Furthermore, there are studies reporting locoregional differences of the microbiome in various colonic locations. For example, a higher incidence of Escherichia coli phylogroup B2 has been described in right-sided versus left-sided CRC. ${ }^{30}$

Our analyses show that MSI-H status, KRAS mutation, and primary CRC sidedness are independent prognosticators of OS. In general, patients with MSI-H status and KRAS mutation had worse OS than those with MSS status and KRAS wild-type. OS was also shorter in patients with right-sided versus left-sided CRC, which is supported in numerous prior reports. ${ }^{31-33}$ Moreover, the prognostic effect of KRAS mutation varied with primary cancer location, as the effect size was larger in left-sided versus right-sided CRC. One explanation for site-specific differences is that proximal CRC may have an overall higher mutation rate, potentially associated with worse prognosis, as shown in the PETACC-3 study and TCGA. ${ }^{28,34}$

In patients with KRAS wild-type CRC, several studies have shown worse outcomes for right-sided versus left-sided cancers. ${ }^{35,36}$ Sinicrope et $\mathrm{al}^{16}$ conducted an extensive analysis of 3,018 patients with stage III CRC and described results similar to ours, with shorter OS among those with right-sided CRC and KRAS mutation. Furthermore, the RASCAL and RASCAL II studies associated KRAS mutation with earlier recurrence and death, although the smaller PETACC-3 and CALGB 89803 studies in stage II and III CRC showed contradictory results. ${ }^{37-40}$ Discrepancies in the prognostic value of KRAS in CRC could possibly originate from varying patient populations and treatment regimens. Furthermore, the specific location of KRAS mutations (codon 12 vs 13) seems to have prognostic impact in CRC. ${ }^{41}$

Although MSI-H has been associated with favorable prognosis in stage II CRC, only few studies have reported on its role in stage IV CRC. ${ }^{42}$ Price et $\mathrm{al}^{43}$ reported on Australian registry data and showed shorter OS in patients with MSI versus MSS status, although no distinction was made between MSI-H and MSI-L. Jin et $\mathrm{al}^{44}$ described a cohort of 1,268 patients with metastatic CRC from the Mayo Clinic and reported shorter OS in those with MSI-H versus MSS status.

Several mechanisms may contribute to inferior outcomes in patients with MSI-H CRC, including reduced efficacy of fluorouracil-based treatments ${ }^{42,45}$ and modification of the treatment effectiveness of vascular endothelial growth factor-targeted agents. ${ }^{46}$ Still, there are some concerns that the coincidence of BRAF status and MSI might confound the prognostic profile of MSI. ${ }^{47}$

Our study is not devoid of limitations, which are mainly inherent to the use of NCDB as the data source. First, given the stratified coding of the NCDB, no distinction between specific systemic treatment protocols is possible, thereby limiting evaluation of the predictive value of KRAS mutation and microsatellite status. Second, the NCDB does not provide additional details on CRC mutations, such as specific codons and microsatellite status, and KRAS status was not available for all patients in the NCDB, raising concerns about patient selection and the generalizability of our results. Third, there have been concerns about the generalizability of the NCDB data to the general population because it might not cover a cohort representative of the US population. Furthermore, the low proportion of patients with data on KRAS and MSI status among all patients with mCRC raises concerns about potential selection bias and variability in institutional policies regarding MSI testing strategies, which might impair the generalizability of our findings to a broader population. 
Finally, evaluating data up to 2016, our analyses did not cover the recent use of immunotherapy for advanced CRC, with particular benefit for patients with MSI-H status.

\section{Conclusions}

In a large-scale US national cohort, we showed that MSI and KRAS status in stage IV CRC vary according to demography, CRC sidedness, and US geography. MSI-H, KRAS mutation, and primary CRC site (right- vs left-sided) independently affect OS with a worsened prognosis and distinct profiles, although recent developments might change outcomes, particularly for patients with MSI-H status. Our results corroborate that generically classifying adenocarcinomas as CRC might not appreciate the observed mutational and sitespecific differences. Additional studies are warranted to evaluate whether these differences translate into site-specific treatment effectiveness for primary or metastatic disease.

Submitted April 16, 2020; accepted for publication July 14, 2020. Published online February 2, 2021.

Author contributions: Study concept: Uhlig, Kim. Data curation: All authors. Formal analysis: Uhlig. Investigation: All authors. Methodology: Uhlig. Project administration: Kim. Resources: Uhlig, Cecchini, Stein, Lacy, Kim. Supervision: Kim. Validation: Uhlig, Sheth, Kim. Visualization: Uhlig. Writing - original draft: All authors

Disclosures: Dr. Uhlig has disclosed that he was a speaker for Bayer Healthcare. Dr. Kim has disclosed that he is a scientific advisor for Boston Scientific, SIRTex, Genentech, Eisai, Amgen, and Bayer, and has received research support from Galil and Flatiron. The remaining authors have disclosed that they have no financial interests, arrangements, affiliations, or commercial interests with the manufacturers of any products discussed in this article or their competitors.

Funding: Dr. Kim is supported by a grant from the US Department of Defense (CA160741). The funder had no role in study design, data collection and analysis, decision to publish, or preparation of the manuscript.

Correspondence: Hyun S. Kim, MD, MHS, University of Maryland School of Medicine, 22 South Greene Street, Suite G2K14, Baltimore, MD 21201. Email: kevin.kim@umm.edu

\section{References}

1. Bray F, Ferlay J, Soerjomataram I, et al. Global cancer statistics 2018 : GLOBOCAN estimates of incidence and mortality worldwide for 36 cancers in 185 countries. CA Cancer J Clin 2018;68:394-424.

2. Gravitz L. Prevention: tending the gut. Nature 2015;521:S6-8.

3. Gurpinar E, Grizzle WE, Piazza GA. NSAIDs inhibit tumorigenesis, but how? Clin Cancer Res 2014;20:1104-1113.

4. Falcone A, Ricci S, Brunetti I, et al. Phase III trial of infusional fluorouracil, leucovorin, oxaliplatin, and irinotecan (FOLFOXIRI) compared with infusional fluorouracil, leucovorin, and irinotecan (FOLFIRI) as first-line treatment for metastatic colorectal cancer: the Gruppo Oncologico Nord Ovest. J Clin Oncol 2007;25:1670-1676.

5. Van Cutsem E, Cervantes A, Adam R, et al. ESMO consensus guidelines for the management of patients with metastatic colorectal cancer. Ann Oncol 2016;27:1386-1422.

6. Grady WM, Carethers JM. Genomic and epigenetic instability in colorectal cancer pathogenesis. Gastroenterology 2008;135:1079-1099.

7. Guo F, Gong $\mathrm{H}$, Zhao $\mathrm{H}$, et al. Mutation status and prognostic values of KRAS, NRAS, BRAF and PIK3CA in 353 Chinese colorectal cancer patients. Sci Rep 2018;8:6076.

8. Le DT, Uram JN, Wang H, et al. PD-1 blockade in tumors with mismatchrepair deficiency. N Engl J Med 2015;372:2509-2520.

9. Le DT, Durham JN, Smith KN, et al. Mismatch repair deficiency predicts response of solid tumors to PD-1 blockade. Science 2017;357:409-413.

10. Amado RG, Wolf $M$, Peeters $M$, et al. Wild-type KRAS is required for panitumumab efficacy in patients with metastatic colorectal cancer. J Clin Oncol 2008:26:1626-1634.

11. Van Cutsem E, Köhne CH, Láng I, et al. Cetuximab plus irinotecan, fluorouracil, and leucovorin as first-line treatment for metastatic colorectal cancer: updated analysis of overall survival according to tumor KRAS and BRAF mutation status. J Clin Oncol 2011;29:2011-2019.

12. Caputo F, Santini C, Bardasi C, et al. BRAF-mutated colorectal cancer: clinical and molecular insights. Int J Mol Sci 2019;20:5369.

13. Hampel H, Frankel WL, Martin E, et al. Screening for the Lynch syndrome (hereditary nonpolyposis colorectal cancer). N Engl J Med 2005; 352:1851-1860

14. Weissman SM, Burt R, Church J, et al. Identification of individuals at risk for Lynch syndrome using targeted evaluations and genetic testing: National Society of Genetic Counselors and the Collaborative Group of the Americas on Inherited Colorectal Cancer joint practice guideline. J Genet Couns 2012;21:484-493.

15. Gupta S, Provenzale D, Regenbogen SE, et al. NCCN Guidelines insights: genetic/familial high-risk assessment: colorectal, version 3.2017. J Natl Compr Canc Netw 2017;15:1465-1475

16. Sinicrope FA, Mahoney MR, Yoon HH, et al. Analysis of molecular markers by anatomic tumor site in stage III colon carcinomas from adjuvant chemotherapy trial NCCTG N0147 (Alliance). Clin Cancer Res 2015;21: 5294-5304.

17. Yamauchi M, Morikawa T, Kuchiba A, et al. Assessment of colorectal cancer molecular features along bowel subsites challenges the conception of distinct dichotomy of proximal versus distal colorectum. Gut 2012;61:847-854.

18. Fujiyoshi K, Yamamoto G, Takenoya T, et al. Metastatic pattern of stage IV colorectal cancer with high-frequency microsatellite instability as a prognostic factor. Anticancer Res 2017;37:239-247.

19. Lowe K, Bylsma LC, Levin-Sparenberg ED, et al. Prevalence of KRAS, NRAS, and BRAF gene mutations in metastatic colorectal cancer patients: a systematic literature review and meta-analysis [abstract]. J Clin Oncol 2019;37(Suppl):Abstract 523.

20. Kafatos G, Niepel D, Lowe K, et al. RAS mutation prevalence among patients with metastatic colorectal cancer: a meta-analysis of real-world data. Biomarkers Med 2017;11:751-760.

21. White A, Vernon SW, Franzini L, et al. Racial disparities in colorectal cance survival: to what extent are racial disparities explained by differences in treatment, tumor characteristics, or hospital characteristics? Cancer 2010; 116:4622-4631.

22. Yoon $\mathrm{HH}$, Shi $\mathrm{Q}$, Alberts $\mathrm{SR}$, et al. Racial differences in BRAF/KRAS mutation rates and survival in stage III colon cancer patients. J Natl Cancer Inst 2015;107:djv186.

23. Marchand LL. Combined influence of genetic and dietary factors on colorectal cancer incidence in Japanese Americans. J Natl Cancer Inst Monogr 1999;1999:101-105.

24. O'Keefe SJ. Diet, microorganisms and their metabolites, and colon cancer. Nat Rev Gastroenterol Hepatol 2016;13:691-706.

25. Limsui D, Vierkant RA, Tillmans LS, et al. Cigarette smoking and colorectal cancer risk by molecularly defined subtypes. J Natl Cancer Inst 2010;102 1012-1022.

26. Fedirko $\mathrm{V}$, Tramacere I, Bagnardi $\mathrm{V}$, et al. Alcohol drinking and colorectal cancer risk: an overall and dose-response meta-analysis of published studies. Ann Oncol 2011;22:1958-1972.

27. Turpin A, Genin M, Hebbar M, et al. Spatial heterogeneity of KRAS mutations in colorectal cancers in northern France. Cancer Manag Res 2019;11:8337-8344

28. The Cancer Genome Atlas Network. Comprehensive molecular characterization of human colon and rectal cancer. Nature 2012;487:330-337.

29. Stintzing S, Tejpar S, Gibbs $P$, et al. Understanding the role of primary tumour localisation in colorectal cancer treatment and outcomes. Eur J Cancer 2017;84:69-80.

30. Kohoutova D, Smajs D, Moravkova P, et al. Escherichia coli strains of phylogenetic group B2 and D and bacteriocin production are associated with advanced colorectal neoplasia. BMC Infect Dis 2014;14:733. 
31. Boisen MK, Johansen JS, Dehlendorff C, et al. Primary tumor location and bevacizumab effectiveness in patients with metastatic colorectal cancer. Ann Oncol 2013;24:2554-2559.

32. Loupakis F, Yang D, Yau L, et al. Primary tumor location as a prognostic factor in metastatic colorectal cancer. J Natl Cancer Inst 2015; 107:dju427.

33. Petrelli F, Tomasello G, Borgonovo K, et al. Prognostic survival associated with left-sided vs right-sided colon cancer: a systematic review and metaanalysis. JAMA Oncol 2017;3:211-219.

34. Missiaglia E, Jacobs B, D'Ario G, et al. Distal and proximal colon cancers differ in terms of molecular, pathological, and clinical features. Ann Oncol 2014;25:1995-2001.

35. Tejpar S, Stintzing S, Ciardiello F, et al. Prognostic and predictive relevance of primary tumor location in patients with RAS wild-type metastatic colorectal cancer: retrospective analyses of the CRYSTAL and FIRE-3 trials. JAMA Oncol 2017;3:194-201.

36. Arnold D, Lueza B, Douillard JY, et al. Prognostic and predictive value of primary tumour side in patients with RAS wild-type metastatic colorectal cancer treated with chemotherapy and EGFR directed antibodies in six randomized trials. Ann Oncol 2017;28:1713-1729.

37. Andreyev HJ, Norman AR, Cunningham D, et al. Kirsten ras mutations in patients with colorectal cancer: the multicenter "RASCAL" study. J Natl Cancer Inst 1998;90:675-684.

38. Andreyev HJ, Norman AR, Cunningham D, et al. Kirsten ras mutations in patients with colorectal cancer: the 'RASCAL II' study. $\mathrm{Br} \mathrm{J}$ Cancer 2001;85:692-696

39. Roth AD, Tejpar S, Delorenzi M, et al. Prognostic role of KRAS and BRAF in stage II and III resected colon cancer: results of the translational study on the PETACC-3, EORTC 40993, SAKK 60-00 trial. J Clin Oncol 2010·28: 466-474.

40. Ogino S, Meyerhardt JA, Irahara N, et al. KRAS mutation in stage III colon cancer and clinical outcome following intergroup trial CALGB 89803. Clin Cancer Res 2009;15:7322-7329.

41. Imamura $Y$, Morikawa T, Liao X, et al. Specific mutations in KRAS codons 12 and 13 , and patient prognosis in 1075 BRAF wild-type colorectal cancers. Clin Cancer Res 2012;18:4753-4763.

42. Hutchins G, Southward K, Handley K, et al. Value of mismatch repair, KRAS, and BRAF mutations in predicting recurrence and benefits from chemotherapy in colorectal cancer. J Clin Oncol 2011 . 29:1261-1270.

43. Price TJ, Karapetis CS, Joanne Y, et al. Outcomes for metastatic colorecta cancer (mCRC) based on microsatellite instability [abstract]. J Clin Oncol 2018;36(Suppl):Abstract 759.

44. Jin Z, Sanhueza CT, Johnson B, et al. Outcome of mismatch repair-deficient metastatic colorectal cancer: the Mayo Clinic experience. Oncologist 2018; 23:1083-1091.

45. Sargent DJ, Marsoni S, Monges G, et al. Defective mismatch repair as a predictive marker for lack of efficacy of fluorouracil-based adjuvant therapy in colon cancer. J Clin Oncol 2010;28:3219-3226.

46. Innocenti F, Ou FS, Qu X, et al. Mutational analysis of patients with colorectal cancer in CALGB/SWOG 80405 identifies new roles of microsatellite instability and tumor mutational burden for patient outcome. J Clin Oncol 2019;37:1217-1227.

47. Goldstein J, Tran B, Ensor J, et al. Multicenter retrospective analysis of metastatic colorectal cancer (CRC) with high-level microsatellite instability (MSI-H). Ann Oncol 2014;25:1032-1038. 
Supplemental online content for:

\section{Microsatellite Instability and KRAS Mutation in Stage IV Colorectal Cancer: Prevalence, Geographic Discrepancies, and Outcomes From the National Cancer Database}

Johannes Uhlig, MD, MPH; Michael Cecchini, MD; Amar Sheth, BS; Stacey Stein, MD;

Jill Lacy, MD; and Hyun S. Kim, MD, MHS

J Natl Compr Canc Netw 2021;19(3):307-318

eFigure 1: Patient Selection Flowchart

eTable 1: Baseline Characteristics According to Microsatellite and KRAS Status

eTable 2: Univariate and Multivariable Logistic Regression Models for KRAS Mutation Outcome

eTable 3: Univariate and Multivariable Logistic Regression Models for MSI-H Outcome

eTable 4: Overall Survival Rates 


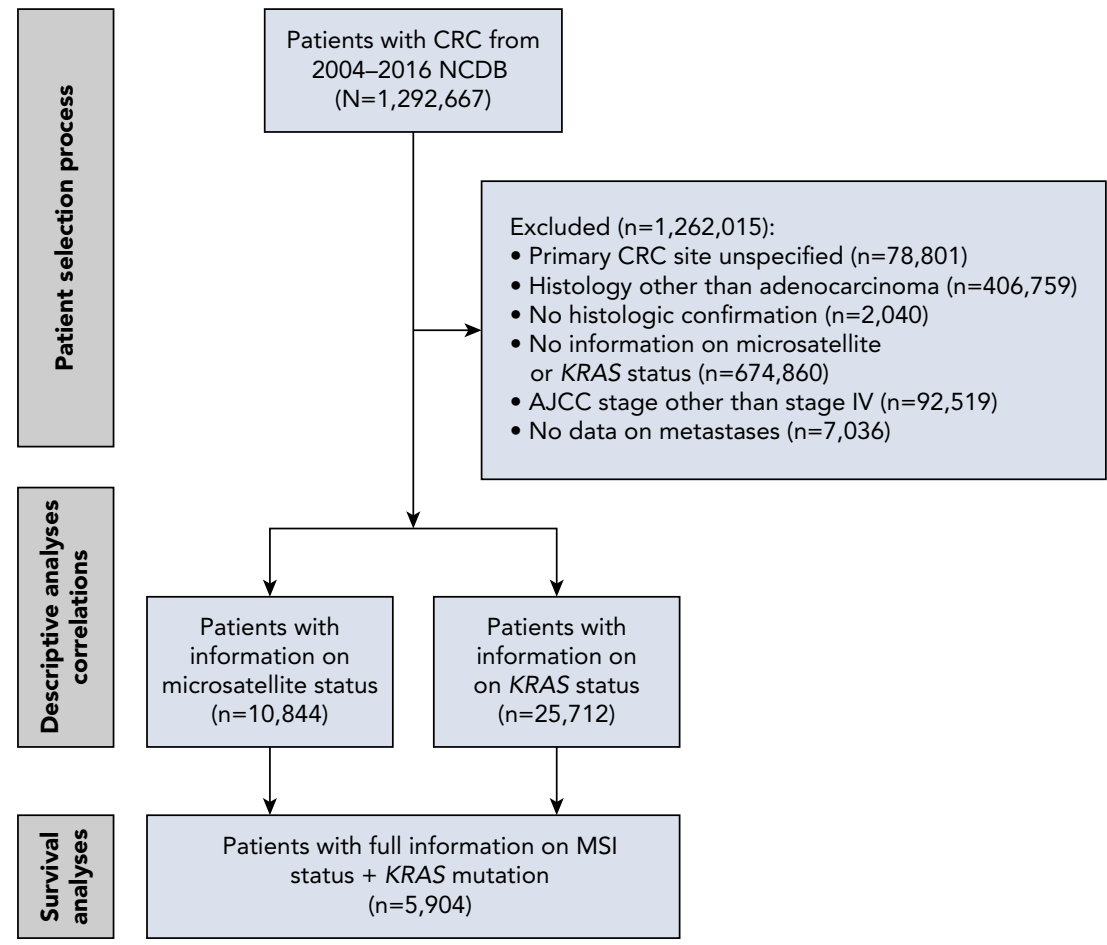

eFigure 1. Patient selection flowchart.

Abbreviations: CRC, colorectal cancer; MSI, microsatellite instability; NCDB, National Cancer Database. 
eTable 1. Baseline Characteristics According to Microsatellite and KRAS Status

\begin{tabular}{|c|c|c|c|c|c|}
\hline & $\begin{array}{l}\text { Total } \\
\text { n (\%) }\end{array}$ & $\begin{array}{c}\text { KRAS Mutation } \\
\mathrm{n}(\%)\end{array}$ & $\begin{array}{c}\text { KRAS Wild-Type } \\
\mathrm{n}(\%)\end{array}$ & $\begin{array}{l}\text { MSI-H } \\
\text { n (\%) }\end{array}$ & $\begin{array}{c}\text { MSS/MSI-L } \\
\text { n (\%) }\end{array}$ \\
\hline Total, N & 5,904 & 2,366 & 3,538 & 187 & 5,717 \\
\hline \multicolumn{6}{|l|}{ Sex } \\
\hline Female & $2,770(46.9)$ & $1,190(50.3)$ & $1,580(44.7)$ & $84(44.9)$ & $2,686(47.0)$ \\
\hline African American & $801(13.6)$ & $393(16.6)$ & $408(11.5)$ & $21(11.2)$ & 780 (13.6) \\
\hline White & $4,789(81.1)$ & $1,857(78.5)$ & $2,932(82.9)$ & $160(85.6)$ & $4,629(81.0)$ \\
\hline Other & $314(5.3)$ & $116(4.9)$ & $198(5.6)$ & $6(3.2)$ & $308(5.4)$ \\
\hline \multicolumn{6}{|l|}{$\mathrm{CCl}$ score } \\
\hline$\geq 3$ & $83(1.4)$ & $38(1.6)$ & $45(1.3)$ & $5(2.7)$ & $78(1.4)$ \\
\hline \multicolumn{6}{|l|}{ Insurance status } \\
\hline None & $282(4.8)$ & $108(4.6)$ & $174(4.9)$ & $8(4.3)$ & $274(4.8)$ \\
\hline Private/Managed care & $3,074(52.1)$ & $1,254(53.0)$ & $1,820(51.4)$ & $78(41.7)$ & $2,996(52.4)$ \\
\hline Medicaid & $604(10.2)$ & $236(10.0)$ & $368(10.4)$ & $20(10.7)$ & $584(10.2)$ \\
\hline Medicare & $1,805(30.6)$ & $715(30.2)$ & $1,090(30.8)$ & 77 (41.2) & $1,728(30.2)$ \\
\hline Other government & $76(1.3)$ & $27(1.1)$ & $49(1.4)$ & $2(1.1)$ & $74(1.3)$ \\
\hline Unknown & $63(1.1)$ & $26(1.1)$ & $37(1.0)$ & $2(1.1)$ & $61(1.1)$ \\
\hline \multicolumn{6}{|l|}{ Cancer location } \\
\hline Rectum & $1,008(17.1)$ & $382(16.1)$ & $626(17.7)$ & $14(7.5)$ & $994(17.4)$ \\
\hline \multicolumn{6}{|l|}{ Treatment } \\
\hline Chemotherapy alone & $1,266(21.4)$ & $515(21.8)$ & $751(21.2)$ & $36(19.3)$ & $1,230(21.5)$ \\
\hline No surgery or chemotherapy & $165(2.8)$ & $64(2.7)$ & $101(2.9)$ & $5(2.7)$ & $160(2.8)$ \\
\hline Surgery without chemotherapy & $607(10.3)$ & $248(10.5)$ & $359(10.1)$ & $33(17.6)$ & $574(10.0)$ \\
\hline Surgery + chemotherapy & $3,866(65.5)$ & $1,539(65.0)$ & $2,327(65.8)$ & $113(60.4)$ & $3,753(65.6)$ \\
\hline \multicolumn{6}{|l|}{ Radiotherapy } \\
\hline No concurrent radiotherapy & $5,234(88.7)$ & $2,107(89.1)$ & $3,127(88.4)$ & $162(86.6)$ & $5,072(88.7)$ \\
\hline Local radiotherapy & $424(7.2)$ & $172(7.3)$ & $252(7.1)$ & $8(4.3)$ & $416(7.3)$ \\
\hline Radiotherapy for metastatic disease & $222(3.8)$ & $77(3.3)$ & $145(4.1)$ & $14(7.5)$ & $208(3.6)$ \\
\hline Y90 radioembolization & $24(0.4)$ & $10(0.4)$ & $14(0.4)$ & $3(1.6)$ & $21(0.4)$ \\
\hline
\end{tabular}




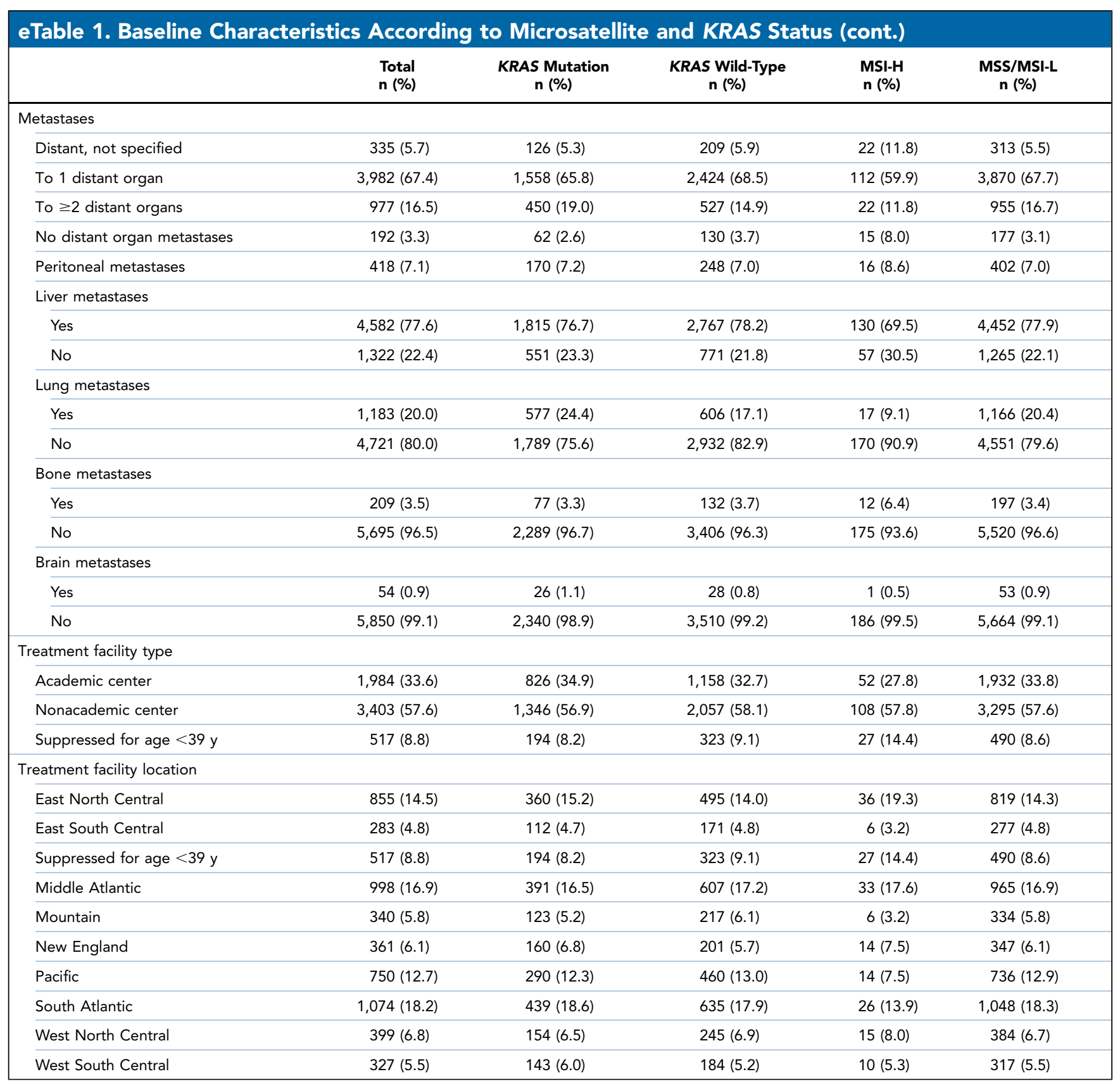

Abbreviations: CCl, Charlson-Deyo comorbidity index; MSI-H, microsatellite instability-high; MSI-L, microsatellite instability-low; MSS, microsatellite status-stable. 
eTable 2. Univariate and Multivariable Logistic Regression Models for KRAS Mutation Outcome

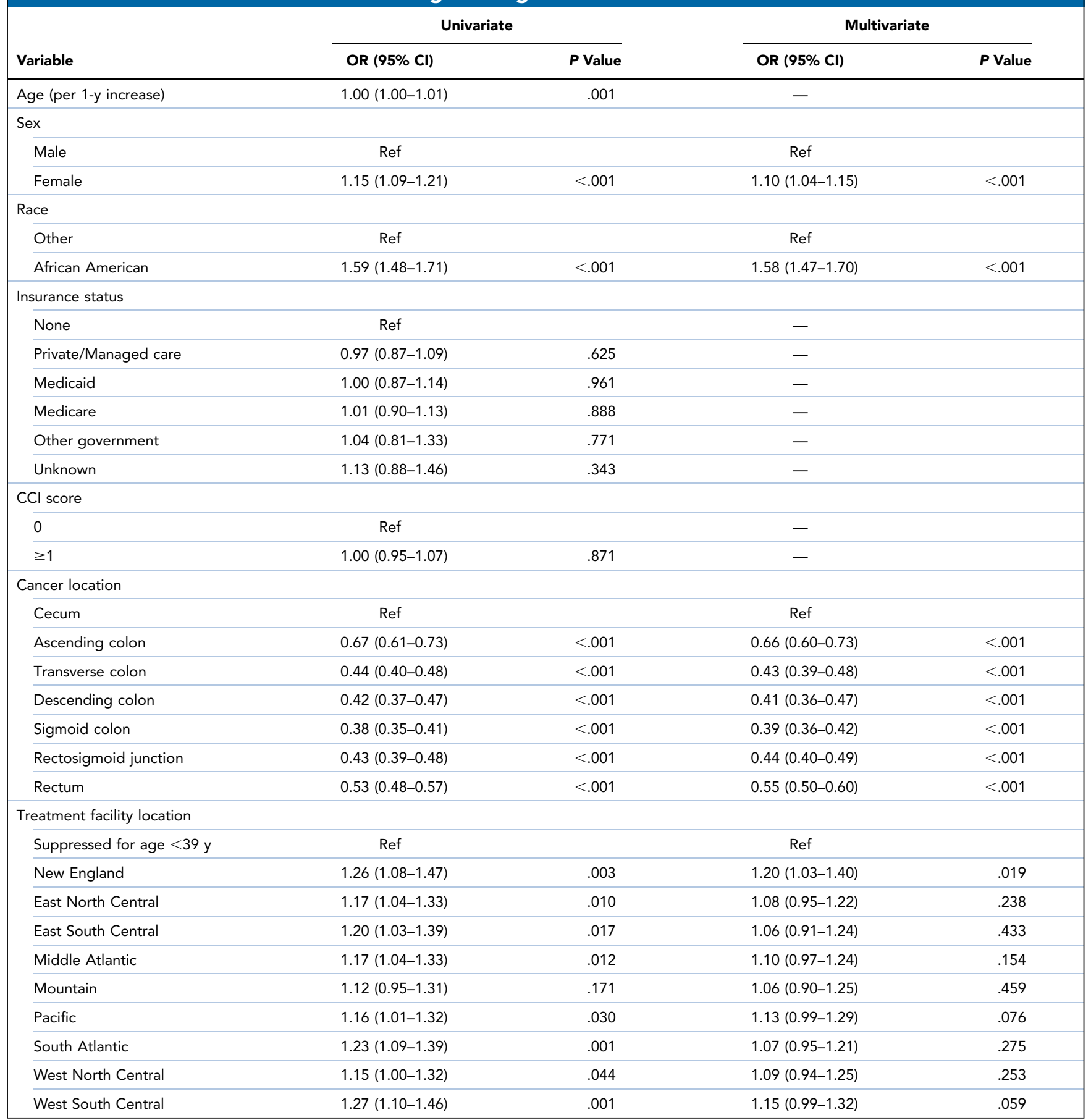

Abbreviations: $\mathrm{CCl}$, Charlson-Deyo comorbidity index; OR, odds ratio. 


\section{eTable 3. Univariate and Multivariable Logistic Regression Models for MSI-H Outcome}

\begin{tabular}{|c|c|c|c|c|}
\hline \multirow[b]{2}{*}{ Variable } & \multicolumn{2}{|c|}{ Univariate } & \multicolumn{2}{|c|}{ Multivariate } \\
\hline & OR $(95 \% \mathrm{Cl})$ & $P$ Value & OR $(95 \% \mathrm{Cl})$ & $P$ Value \\
\hline Age (per 1-y increase) & $1.01(1.00-1.02)$ & .072 & - & \\
\hline \multicolumn{5}{|l|}{ Sex } \\
\hline Female & Ref & & - & \\
\hline Male & $1.11(0.89-1.38)$ & .350 & - & \\
\hline \multicolumn{5}{|l|}{ Race } \\
\hline African American & Ref & & - & \\
\hline Other & $1.34(0.96-1.93)$ & .101 & - & \\
\hline \multicolumn{5}{|l|}{ Insurance status } \\
\hline None & Ref & & - & \\
\hline Private/Managed care & $0.66(0.42-1.10)$ & .094 & - & \\
\hline Medicaid & $0.92(0.54-1.64)$ & .780 & - & \\
\hline Medicare & $1.03(0.65-1.70)$ & .915 & - & \\
\hline Other government & $0.79(0.23-2.13)$ & .673 & - & \\
\hline Unknown & $0.64(0.15-1.89)$ & .471 & - & \\
\hline \multicolumn{5}{|l|}{$\mathrm{CCl}$ score } \\
\hline 0 & Ref & & - & \\
\hline$\geq 1$ & $0.84(0.64-1.09)$ & .195 & - & \\
\hline \multicolumn{5}{|l|}{ Cancer location } \\
\hline Cecum & Ref & & Ref & \\
\hline Ascending colon & $0.94(0.65-1.34)$ & .725 & $0.93(0.65-1.33)$ & .696 \\
\hline Transverse colon & $1.22(0.88-1.70)$ & .230 & $1.19(0.85-1.66)$ & .302 \\
\hline Descending colon & $0.76(0.44-1.24)$ & .296 & $0.72(0.42-1.18)$ & .209 \\
\hline Sigmoid colon & $0.51(0.36-0.72)$ & $<.001$ & $0.49(0.35-0.69)$ & $<.001$ \\
\hline Rectosigmoid junction & $0.36(0.21-0.60)$ & $<.001$ & $0.34(0.19-0.57)$ & $<.001$ \\
\hline Rectum & $0.42(0.28-0.63)$ & $<.001$ & $0.40(0.27-0.60)$ & $<.001$ \\
\hline \multicolumn{5}{|l|}{ Treatment facility location } \\
\hline Middle Atlantic & Ref & & Ref & \\
\hline East North Central & $1.03(0.74-1.45)$ & .848 & $1.03(0.73-1.45)$ & .871 \\
\hline East South Central & $0.55(0.28-0.98)$ & .056 & $0.55(0.28-0.99)$ & .059 \\
\hline Suppressed for age $<39$ y & $1.14(0.75-1.72)$ & .531 & $1.33(0.86-2.01)$ & .190 \\
\hline Mountain & $0.39(0.18-0.75)$ & .009 & $0.40(0.18-0.76)$ & .010 \\
\hline New England & $0.73(0.42-1.20)$ & .229 & $0.72(0.42-1.18)$ & .210 \\
\hline Pacific & $0.46(0.28-0.72)$ & .001 & $0.47(0.29-0.73)$ & .001 \\
\hline South Atlantic & $0.63(0.43-0.91)$ & .014 & $0.61(0.42-0.89)$ & .010 \\
\hline West North Central & $0.71(0.41-1.15)$ & .179 & $0.69(0.41-1.13)$ & .160 \\
\hline West South Central & $0.79(0.48-1.27)$ & .356 & $0.79(0.47-1.27)$ & .349 \\
\hline
\end{tabular}

Abbreviations: $\mathrm{CCl}$, Charlson-Deyo comorbidity index; MSI-H, microsatellite instability-high; OR, odds ratio. 
6 - Uhlig et al

\section{eTable 4. Overall Survival Rates}

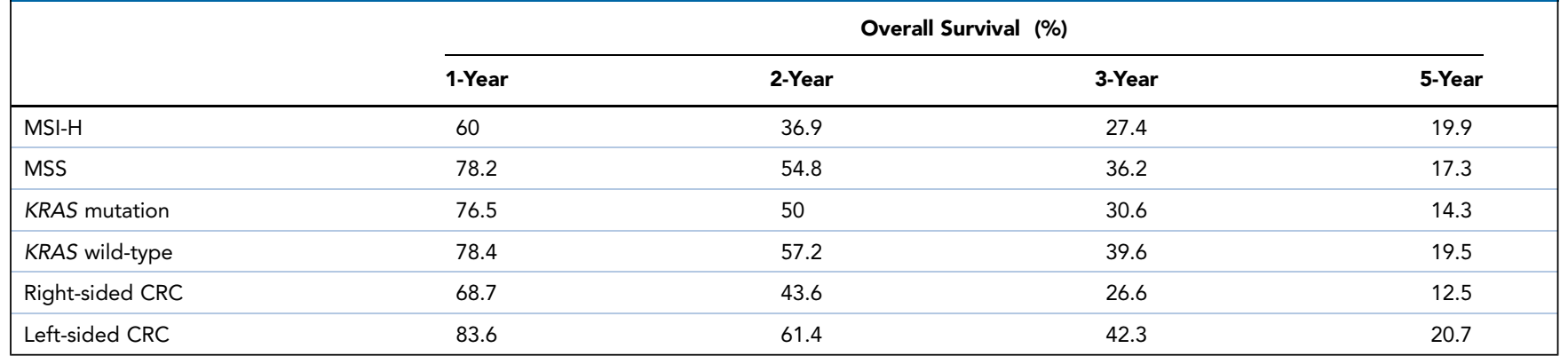

Abbreviations: CRC, colorectal cancer; MSI-H, microsatellite instability-high; MSS, microsatellite status-stable. 